\title{
Elektrospinning Yöntemiyle Üretilmiş Farklı Çaplardaki Yapay Damarların Mekanik Özelliklerinin İncelenmesi
}

\author{
Investigation of Mechanical Properties of Artificial Vessels of Different Diameters Produced \\ by Electrospinning Method
}

\author{
Ahmet Talat INAN ${ }^{1}$ (i), Merve Mine ŞEKER ${ }^{1}$ \\ ${ }^{1}$ Marmara Üniversitesi, Teknoloji Fakültesi, Makine Mühendisliği Bölümü, 34722, İstanbul, Türkiye
}

$\ddot{O} z$

Bu çalışmada, PLA ve PCL polimeri kullanılarak, geniş malzeme seçenekleri ve üretim parametrelerinde esneklik sunularak damar imalatı yapılmıştır. Farklı kalınlıklarda tasarımı ve imalatı gerçekleştirilmiş olan damarın mekanik özellikleri incelenmiş ve sonuçları değerlendirilmiştir. Dönen farklı çaplardaki $(2 \mathrm{~mm}, 3 \mathrm{~mm}, 4 \mathrm{~mm}$ ve $5 \mathrm{~mm})$ kollektörlerin üzerinde, farklı konsantrasyonlardaki PLA ve PCL polimerleriyle, elektro-eğirme yöntemi kullanılarak morfolojik ve mekanik olarak bir kan damarına benzeyen iskele mimarisi geliştirilmiştir. $\mathrm{Bu}$ iskeleler oluşturulurken, spinleme parametreleri (uygulanan voltaj, akış hızı, kollektörün dönüş hızı, uç ile kolektör arası mesafe) değiştirilerek baloncuksuz optimum yüzeye ulaşılması amaçlanmıştır. Elde edilmiş ve optimizasyonu yapılmış boru iskelelerinin, Scanning Electron Microscopy (Taramalı Elektron Mikroskobu)(SEM), Fourier Transform Infrared Spektrofotometre (Fourier Dönüşümü Kızılötesi Spektrofotometresi) (FTIR) ve çekme testi yardımıyla morfolojik, kimyasal ve mekanik özellikleri tespit edilmiş olup, hangi solüsyon konsantrasyonun kullanılması gerektiği belirlenmiştir. Yapılan testler sonucunda \%8 PLA ve \%10'luk PCL konsantrasyonunun uygun değer olduğu görülmüştür. Ayrıca eğirme parametrelerine baktığımızda her ikisinin de uygun değer çözeltileri için uç ile kolektör arası mesafe $20 \mathrm{~cm}$, uygulanan voltaj $20 \mathrm{kV}$ ve akış hızı için 1,5 ml/h uygun bulunmuştur. Kolektörlerin çaplarına göre dönme hızları ise $2 \mathrm{~mm}$ için $70 \mathrm{rpm}, 3 \mathrm{~mm}$ çap için $60 \mathrm{rpm}$, 4 ve $5 \mathrm{~mm}$ çaplarındaki kolektörler için ise $50 \mathrm{rpm}$ döndürme hızlarının optimum olduğu görülmüştür.

Anahtar Kelimeler: Elektro-Eğirme, Yapay Damar, Doku Mühendisliği, Polimer Bilimi.

\begin{abstract}
In this study, the design and production of vessel manufacturing at different thicknesses using PLA and PCL polymers and optimum mechanical properties for the system were investigated. Scaffolding architecture, which morphologically and mechanically resembles a blood vessel, has been developed by electrospinning with different concentrations of PLA and PCL polymers on rotating collectors of different diameters $(2 \mathrm{~mm}, 3 \mathrm{~mm}, 4 \mathrm{~mm}$ and $5 \mathrm{~mm})$. While making these scaffoldings, it was aimed to reach the optimum surface without bubble by changing the spin parameters (applied current, flow rate, rotation speed of collector, distance between tip and collector). The morphological, chemical and mechanical properties of the optimized tube scaffoldings were determined by Scanning Electron Microscopy, Fourier Transform Infrared Spectrophotometry and tensile tests and the solution concentration was determined. As a result of the tests, $8 \%$ PLA and 10\% PCL concentration were found to be optimum. When we look at the Spinning parameters, the distance between the tip and the collector is about $20 \mathrm{~cm}$, the applied voltage is $20 \mathrm{kV}$, and the flow rate is $1.5 \mathrm{ml} / \mathrm{h}$ for optimum solutions for both. According to the diameters of the collectors, rotation speeds of $70 \mathrm{rpm}$ for $2 \mathrm{~mm}, 60 \mathrm{rpm}$ for $3 \mathrm{~mm}$ diameter, and $50 \mathrm{rpm}$ for 4 and $5 \mathrm{~mm}$ diameter collectors were found to be optimum.
\end{abstract}

Keywords: Electrospinning, Artificial Vein, Tissue Engineering, Polymer Science.

\section{GİRIS}

Kardiyovasküler hastalıklarda, diyaliz ve kalp ameliyatları gibi durumlarda, kan akışında plak oluşumu ve tıkanmalar nedeniyle damar değişimine ihtiyaç duyulmaktadır. Bu damar değişimi de klinik başarısı sınırlı olup maliyeti de oldukça yüksektir. Sentetik yapay damarlar için 1956 yılından itibaren yapılan çalışmalarda $6 \mathrm{~mm}$ den büyük geniş çaplı damarlar için damar değişimi uygun olsa da, küçük çaplarda ki damarlarda başarı sağlanamamıştır [1]. 2001 yılında, Shinoka ve arkadaşları, doku mühendisliği vasküler yapının ilk klinik kullanımını bildirmiş̧lerdir. Yapay damar dört yaşında bir kız çocuğuna, tıkalı bir pulmoner arteri yeniden yapılandırmak için implante edilmiştir [2].

Damar iskeleleri hazırlamak için faz ayırma, kendiliğinden ayırma, çekme, eğirmeli bağlama, elektrospinning (elektro eğirme) gibi metotlar denenmiştir. Avantajları sebebiyle en çok tercih edileni ise elektrospinning yöntemidir (elektro eğirme) [3]. Bir sıvı çözeltiye, kontrollü elektrik alan kuvveti uygulanması temeline dayanır. $\mathrm{Bu}$ yöntemle doğal kan damarına benzeyen nanometre ile mikrometre aralığında değişen fiber çaplı lifli iskeleler üretilir. Fonksiyonel iskele geliştirmek için malzeme mühendisleri, makine mühendisleri, hücre kültürü 
biyologları, klinisyenler ve farklı alanlarda birçok uzmanın iş birliği gerekmektedir. Elektrospinning (elektro eğirme) tekniği, polimerlerden nano liflerden oluşan boru şeklindeki yapılar üretmek için kullanılır. PCL / poli etilen oksit ve PCL / PLGA'dan [4] yapılan yap1 iskeleleri, hayvan modellerinde test edilmiştir.

Sentetik damar kullanımına ilişkin ilk rapor, 1952 y1lına Voorhees ve arkadaşları tarafindan köpeklerde Vinyon N kumaș tüpler kullanılmasıyla hazırlanmıștır [5]. Bu rapordan önce, bilim adamları doğal arterleri kanal olarak kullanmaya odaklanmışlardır. Takip eden yıllarda, pasif olarak kanın minimal reaksiyonla taşınmasını amaçlayan diğer sentetik malzemeler geliştirilmiş olup bu da polietilen tereftalat (Dacron) ve genişletilmiş politetrafloroetilin klinik başarısına yol açmıştır.

1986 yılında Weinberg ve Bell'in simgesel yayınında, yapay bir damar oluşturmasında sığır hücrelerinin sıçan kollajen jeli ile kullanımını açıklamıştır [6]. 1998 yılında, Shinoka ve arkadaşları, önce düşük basınçlı bir pulmoner arter sisteminde uzun vadeli otolog implantasyonunu gösteren, biyolojik olarak parçalanabilen sentetik bir yapı iskelesinin, küçük hücreli hücrelerin kullanımını tanımlamışlardır [7]. L'Heureux ve ark., tarafindan 1998 yılında yapılan bir çalışmada insan hücrelerini kullanan ve yüksek basınçlı bir arteryel bypass modelinde kısa süreli bir ksenojenik implant olarak test edilen bir mühendislik damar iskelesi meydana getirmişler ve yayınlamışlardır [8] 1999 'da Niklason ve arkadaşları ve Shum-Tim ve ark. biyobozunur bir polimerde otolog domuz / küçük hücrelerin kullanılmasıyla, in vitro ortamda yetiştirilen bir arter oluşumunu incelemişlerdir. Yapılan bu çalışmada Niklason ve arkadaşları küçük çaplı greftler kullanıp damarları iskelelerini kısa vadeli arter basıncı altında incelemişlerdir [9]. Shum-Tim ve arkadaşları ise uzun süren süreç değerlendirmesi sonucunda düşük basınç altında çalışılan büyük çaplı greftler geliştirmişlerdir [10].

L'Heureux ve arkadaşları 2007 yılında vasküler doku mühendisliği üzerine yaptıkları çalışma ile kan damarlarını klinik olarak, başarısız arteriyo-venöz şantların yerine kullanmıştır [11]. Bu da vasküler doku mühendisliği için bir dönüm noktası olmuştur. Wise ve ark., 2011 yılında minimum 1700 mm Hg patlama basıncıyla vaskülar greftlerin mekanik özelliklerinin doğal dokuya benzerliklerini keşfetmiştir [12]. İmalat sürecinde klinik olarak iyi sonuçlar elde etmek için, greft'in saklanması hazirlanması ve implantasyon sırasında kolayca uyum sağlayabilme yeteneği 2015 yılında G.N. Tan ve arkadaşları tarafindan açıklanmıştır [13].

$\mathrm{Bu}$ çalışmada, Elektrospinning (elektroeğirme) yöntemi kullanılarak tasarımlanan ve imal edilen farklı kalınlıklardaki damarların mekanik özellikleri incelenerek elde edilen bulgularla ilgili değerlendirmeler yapılmıştır.

\section{MATERYAL VE YÖNTEM}

Damar imalatı yapılan bu çalışmada PLA ve PCL polimerleri kullanılarak damar imalatı için elektrospinning (elektroeğirme) cihazı kullanılmıştır. İmalatı gerçekleştirilen damarlarn analizinde FTIR ve SEM cihazları kullanılmıştır. Damarların dayanıklılığının ölçümünde ise çekme cihazı kullanılarak testler yapılmıştır. Fiziksel özelliklerini ölçmek için ise 2.1.5. Bölümünde isimleri yazılan cihazlar kullanılmıştır. $\mathrm{Bu}$ işlemlerden sonra ise deneysel çalışmalara başlanmıştır. Morfolojik ve mekanik özellikler, bozunabilirlik, işlenebilirlik ve biyouyumluluk açısından uygun yapay kan damarları üretmek için polimer seçimi önemlidir. Damar üretiminde sentetik polimerler doğal polimerlerden daha iyi mekanik özellik gösterirler [14].

Polimerlerin farklı kalınlıklardaki kollektörler üzerinde parametreler değiştirilerek elektrospinninglenmesiyle (elektroeğirilmesi) oluşan iskelelerin yapısal ve mekanik özelliklerinin tespit edilmesi için Scanning Electron Microscopy (SEM), çekme testi, ve Fourier Transform Infrared Spektrofotometre (FTIR) kullanılmaktadır. SEM, elekron-madde etkileşimlerini kullanarak bir numunenin yüzeyinin yüksek çözünürlüklü görüntülerini üretebilen elektron mikroskobu tekniğidir. Çekme testi ise polimerin dayanabileceği gerilme mukavemetini belirlemek için kullanılır. Polimerin, süneklik, gevreklik, tokluk gibi bilgileri çekme testi sonucunda oluşturulan gerilme gerinim grafiğinden elde edilir. FTIR cihazı, gönderdiği kızılötesi radyasyonla numunedeki polimerde adeta bir spektral parmak izi üreterek kimyasal yapısının tanımlanmasını sağlar.

Farklı kalınlıklardaki kollektörler üzerine sentetik polimer elektrospinlenerek (elektroeğirmekle), morfolojik ve mekanik olarak bir kan damarınınkine benzeyen iskele sistemi oluşturulabilmesi amaçlanmıştır. İyi biyouyumluluğu, biyobozunur olması, yumuşak ve sert dokuya uyumlu biyoemilebilir bir polimer olduğu için, poli-laktik asit, PLA, (sert ve parçalanabilir) tercih edilmiştir. Oluşan boru iskelelerinin yapılan testlerle kan damarı prototipi olarak uygulanabilirliklerinin değerlendirilmesi amaçlanmıştır. İlk olarak farklı konsantrasyonlarda hazırlanan solüsyonlarla düzgün yüzeyli ve baloncuksuz boru iskeleleri oluşturmak amaçlanmış, bunun içinde spinning (eğirme) parametreleri her bir kollektör için ayrı ayrı değiştirilip, iyileştirilmiştir. Oluşan farklı çaplardaki iskeleler mekanik, morfolojik ve kimyasal testlerden geçirilip optimum konsantrasyon gözlemlenmiştir. Optimum konsantrasyonu öğrenmek için, polimer $\% 8, \% 10$ ve $\%$ 12 oranlarında Kloroform içinde çözünmüş ve oluşan solüsyona esnekliği artırması için \%3 oranında Tween eklenmiştir.

Özel tasarlanmış elektrospinleme (elektroeğirme) aparatı, pozitif yüksek voltajlı güç kaynağından bir şırınga pompasından, plastik bir şırıngadan, 
hipodermik bir iğneden ve topraklanmış paslanmaz çelikten dönen mandrelden oluşur. Oluşan solüsyonlarla, elektrospinning (elektroeğirme) cihazındaki 2,3,4 ve $5 \mathrm{~mm}$ çapındaki kollektörlerde, polimer dozaj hızı, voltaj, iğne ucu ile kollektör arasındaki mesafe ve mandrel dönüş hızları değiştirilerek boru iskeleleri oluşturulmuştur. Elektrospinleme (elektroeğirme) süresi, her bir boru iskelesi için 1 saat olarak ayarlanmıştır. Elektrospinleme (elektroeğirme) işleminden sonra, boru şeklindeki iskele gece boyunca kurutulmuş ve çıkarılmıştır.

Oluşan vasküler greftlerin yüksek çözünürlüklü görüntüleri, taramalı elektron mikroskopu (SEM) ile, kimyasal yap1s1, Fourier Transform Infrared Spectroscopy (FTIR) ile polimerin dayanabileceği gerilme mukavemeti ise kesilen $40 \mathrm{~mm}$ 'lik örneklerle çekme testiyle ile ölçülüp yapısal ve mekanik testleri ölçülerek deney tamamlanmıştır.

\subsection{Araştırma Araçları}

\subsubsection{Elektrospinning (elektroeğirme) cihazı}

Elektrospinning (elektroeğirme) tekniğinin uygulanması için tipik düzenek Şekil 2.1. de gösterildiği gibi, içinden polimer çözeltisinin atılması gereken bir kılcal kısımdan (iğne, koni, vb.) oluşur; biri çözelti çıkış noktasına ve diğeri doğrudan kollektör plakasına (iletken metal levha, dönen mandrel vb.) bağlanması gereken iki elektrotu olan yüksek voltajlı bir kaynak olup, burada çözücünün buharlaştırılmasından sonra elyaflar birikmektedir.

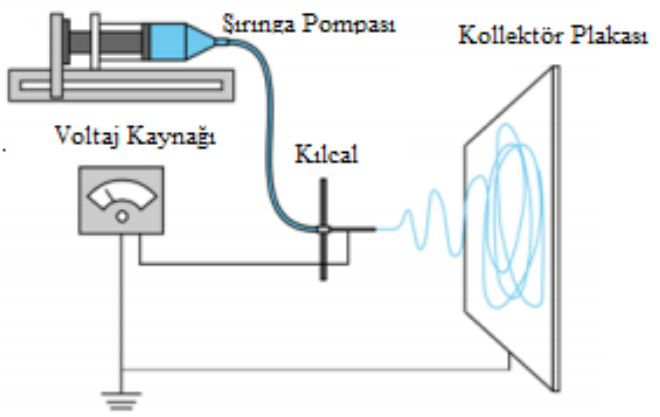

Şekil 2.1. Elektrospinning (elektroeğirme) cihazının şematik kurulum diyagramı

Elektrospinning (elektroeğirme) cihazı olarak (Tri3ot, yerli yapım), güç kaynağı $(0-40 \mathrm{kV}$, Inovenso) ve programlanabilir şırınga pompası (IPS-12, Inovenso) kullanılmıştır.

\subsubsection{FTIR cihazı}

Fourier Transform Infrared Spectroscopy (FTIR) cihazı, (Jasco, FT/IR-4700) gönderdiği kızılötesi radyasyonla numunedeki polimerde adeta bir spektral parmak izi üreterek kimyasal yapısının tanımlanmasını sağlar. Spektrumu, 4000-400 $\mathrm{cm}^{-1}$ aralığında belirlenmiştir.

\subsubsection{SEM cihaz}

Scanning Electron Microscopy (SEM) taramalı elektron, elektron-madde etkileşimlerini kullanarak bir numunenin yüzeyinin yüksek çözünürlüklü görüntülerini üretebilen elektron mikroskobu tekniğidir. Önce iletkenlik kazanması için 1 dakika boyunca kaplama makinesiyle (Quorum, SC7620) Altın (AU) kaplanan numuneler SEM cihazında (Zeiss, MA/EVO10)incelenmiştir.

\subsection{4. Çekme cihazı}

Çekme cihazı ile polimerin dayanabileceği gerilme mukavemeti tespit edilir. Polimerin, süneklik, gevreklik, tokluk gibi bilgileri çekme testi sonucunda oluşturulan gerilme gerinim grafiğinden elde edilir. Çekme cihazı Shimadzu EZ-LX 4411 modelidir. Test sonuçları, özel bir bilgisayar programıyla (Bluehill 2, Elancourt, Fransa) test edilmiştir.

\subsubsection{Solüsyonun fiziksel özelliklerini ölçen cihazalar} Kullanılan farklı konsantrasyonlardaki PLA ve PCL polimerlerinin yoğunluğu, (DIN ISO 3507-GAYLUSSAC (Boru Cam, 10 ml., Türkiye)) piknometreyle, yüzey gerilimi (Biolin Scientific, Sigma 703D, Finlandiya) yüzey gerilim cihazı ile vizkositesi, viskozimetre (Brookfield, DV-E, ABD) ile, iletkenliği taşınabilir iletkenlik cihazı (WTW, Cond 3110, Almanya) ile ölçülmüştür. Terazi olarak (XB 320 A, Precisa, Almanya) hassas terazi ve (MR Hei-Standart, Heidolph) manyetik karıştırıcı kullanılmıştır.

\subsection{Deneyin Yapılışı}

Farklı kolektör çapları için uygun değer bulanan elektrospinning (elektroeğirme) parametreleri hem PLA için hem de PCL için Tablo 2.2.1'de, imal edilen yapay damar örnekleri ise Şekil 2.2'de gösterilmiştir.

Tablo 2.2.1. PLA ve PCL'için farklı çaplardaki kolektörlerde spinlenme (eğirme) parametreleri

\begin{tabular}{|c|c|c|c|c|}
\hline $\begin{array}{c}\text { Kollekör } \\
\text { Çapı(mm) }\end{array}$ & $\begin{array}{c}\text { Uygulanan } \\
\text { Voltaj (Kv) }\end{array}$ & $\begin{array}{c}\text { Akış } \\
\text { Hızı } \\
(\mathrm{ml} / \mathrm{sa})\end{array}$ & $\begin{array}{c}\text { Kolektörün } \\
\text { Dönüş Hızı } \\
(\mathrm{rpm})\end{array}$ & $\begin{array}{c}\text { Uç ile } \\
\text { Kolektör } \\
\text { Aras1 } \\
\text { Mesafe } \\
(\mathrm{cm})\end{array}$ \\
\hline $2 \mathrm{~mm}$ & $20.0 \mathrm{kV}$ & $\begin{array}{c}1.5 \\
\mathrm{ml} / \mathrm{sa}\end{array}$ & $70 \mathrm{rpm}$ & $20 \mathrm{~cm}$ \\
\hline $3 \mathrm{~mm}$ & $20.0 \mathrm{kV}$ & $\begin{array}{c}1.5 \\
\mathrm{ml} / \mathrm{sa}\end{array}$ & $60 \mathrm{rpm}$ & $20 \mathrm{~cm}$ \\
\hline $4 \mathrm{~mm}$ & $20.0 \mathrm{kV}$ & $\begin{array}{c}1.5 \\
\mathrm{ml} / \mathrm{sa}\end{array}$ & $50 \mathrm{rpm}$ & $20 \mathrm{~cm}$ \\
\hline $5 \mathrm{~mm}$ & $20.0 \mathrm{kV}$ & $\begin{array}{c}1.5 \\
\mathrm{ml} / \mathrm{sa}\end{array}$ & $50 \mathrm{rpm}$ & $20 \mathrm{~cm}$ \\
\hline
\end{tabular}



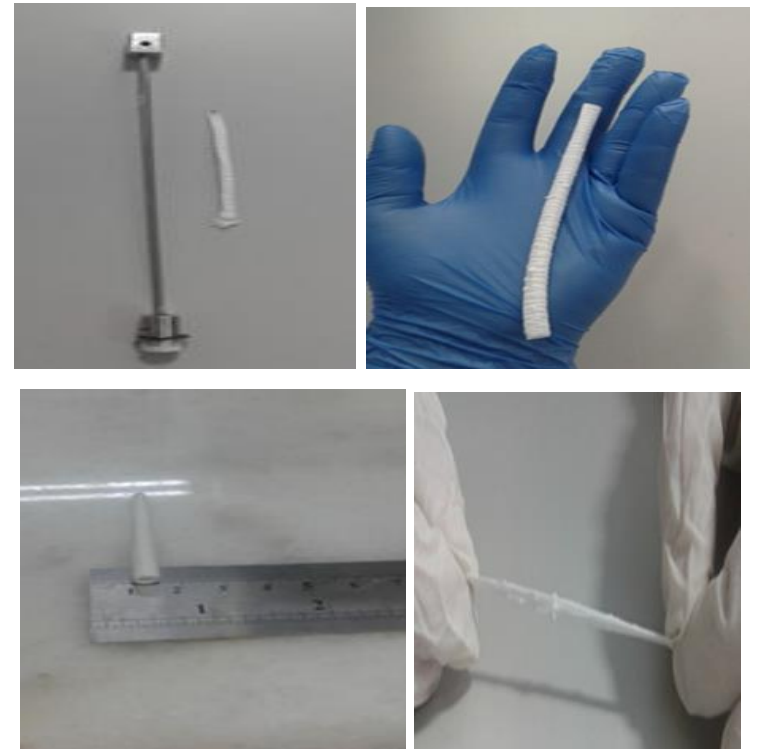

Şekil 2.2. İmalatı yapılan yapay damar örnekleri

\section{BULGULAR VE TARTIŞMA}

\subsection{Fiziksel Özellikler}

Hazırlanan solüsyonların fiziksel özellikler, PLA için Tablo 3.1'de ve PCL için ise, Tablo 3.2'de gösterildiği gibidir.

Tablo 3.1. PLA solüsyonlarının fiziksel özellikleri

\begin{tabular}{|c|c|c|c|c|}
\hline $\begin{array}{c}\text { Örnek } \\
\text { Ad1 } \\
(\text { Ağılık } \\
\text { Oranı) }\end{array}$ & $\begin{array}{c}\text { Yoğunluk } \\
\left(\mathrm{kg} \mathrm{m}^{-3}\right)\end{array}$ & $\begin{array}{c}\text { Elektriksel } \\
\text { Iletkenlik } \\
\left(\mu . \mathrm{S} \mathrm{cm}^{-1}\right)\end{array}$ & $\begin{array}{c}\text { Viskozite } \\
(\mathrm{mPa} . S)\end{array}$ & $\begin{array}{c}\text { Yüzey } \\
\text { Gerilimi } \\
\left(\mathrm{mN} \mathrm{m}^{-1}\right)\end{array}$ \\
\hline $\begin{array}{c}\text { PLA } \\
(\% 8)\end{array}$ & $1400 \pm 2,0$ & $1,21 \pm 0,05$ & $45,2 \pm 0,1$ & $28,54 \pm 0,6$ \\
\hline $\begin{array}{c}\text { PLA } \\
(\% 10)\end{array}$ & $1611 \pm 2,0$ & $1,30 \pm 0,05$ & $54,6 \pm 0,1$ & $27,9 \pm 0,6$ \\
\hline $\begin{array}{c}\text { PLA } \\
(\% 12)\end{array}$ & $1823 \pm 2,0$ & $1,39 \pm 0,05$ & $59,4 \pm 0,1$ & $29,2 \pm 0,6$ \\
\hline
\end{tabular}

Tablo 3.2. PCL solüsyonlarının fiziksel özellikleri

\begin{tabular}{|c|c|c|c|c|}
\hline $\begin{array}{c}\text { Örnek } \\
\text { Ad1 } \\
(\text { Ağıllk } \\
\text { Oranı) }\end{array}$ & $\begin{array}{c}\text { Yoğunluk } \\
\left(\mathrm{kg} \mathrm{m}^{-3}\right)\end{array}$ & $\begin{array}{c}\text { Elektriksel } \\
\text { İletkenlik } \\
\left(\mu . \mathrm{S} \mathrm{cm}^{-1}\right)\end{array}$ & $\begin{array}{c}\text { Viskozite } \\
(\mathrm{mPa} . \mathrm{S})\end{array}$ & $\begin{array}{c}\text { Yüzey } \\
\text { Gerilimi } \\
\left(\mathrm{mN} \mathrm{m}^{-1}\right)\end{array}$ \\
\hline $\begin{array}{c}\text { PCL } \\
(\% 8)\end{array}$ & $1032 \pm 2,0$ & $1,10 \pm 2,0$ & $148,2 \pm 0,1$ & $29,5 \pm 0,6$ \\
\hline $\begin{array}{c}\text { PCL } \\
(\% 10)\end{array}$ & $1250 \pm 2,0$ & $1,10 \pm 0,05$ & $156 \pm 0,1$ & $29,2 \pm 0,6$ \\
\hline $\begin{array}{c}\text { PCL } \\
(\% 12)\end{array}$ & $1448 \pm 2,0$ & $1,20 \pm 0,05$ & $162,3 \pm 0,1$ & $28,142 \pm 0,6$ \\
\hline
\end{tabular}

PLA ve PCL için farklı ağırlık oranlarındaki \%8, \%10 ve $\% 12$ için yoğunluk, elektriksel iletkenlik, viskozite ve yüzey gerilimleri gibi elde edilen fiziksel özellikler tablolardaki gibidir. Kolektörlerde spinlenme (eğirme) parametrelerinin nanofiber çapına etkisi ise Tablo 3.3'de gösterilmiştir. Uygulanan voltajın, polimer konsantrasyon oranının artışı, akış hızının artması ile uç ve kolektör mesafesinin ve çözücü iletkenliğin azalmasının çapı arttırdı̆̆ düşürdüğü görülmüştür.

Tablo 3.3. Farklı parametrelerin nanofiber çapına etkisi

\begin{tabular}{|c|c|c|}
\hline Parametre & $\begin{array}{c}\text { Nanofiber Çapına } \\
\text { Etkisi }\end{array}$ & Referans \\
\hline $\begin{array}{l}\text { Uygulanan } \\
\text { Voltaj }\end{array}$ & $\begin{array}{l}\text { Voltajın artmas1, } \\
\text { çap1 arttırır. }\end{array}$ & $\begin{array}{l}\text { Meechaisue ve } \\
\text { ark., [15] }\end{array}$ \\
\hline Akış H1zı & $\begin{array}{c}\text { Akımın artmas1, çap1 } \\
\text { arttırır. }\end{array}$ & $\begin{array}{c}\text { Zuo, W ve ark. } \\
{[16]}\end{array}$ \\
\hline $\begin{array}{l}\text { Uç ve Kollektör } \\
\text { Mesafesi }\end{array}$ & $\begin{array}{c}\text { Mesafe azaldıkça, } \\
\text { çap artar. }\end{array}$ & $\begin{array}{c}\text { Chase ve ark. } \\
\text { [17] }\end{array}$ \\
\hline $\begin{array}{c}\text { Polimer } \\
\text { Konsantrasyonu }\end{array}$ & $\begin{array}{l}\text { Oranın artması, çap } 1 \\
\text { arttırır. }\end{array}$ & $\begin{array}{c}\text { Zheng, J ve ark. } \\
{[18]}\end{array}$ \\
\hline Yüzey Gerilimi & $\begin{array}{l}\text { Etkisi ihmal } \\
\text { edilebilir. }\end{array}$ & $\begin{array}{c}\text { Thompson, C. } \\
\text { ve ark. [19] }\end{array}$ \\
\hline $\begin{array}{l}\text { Çözücü } \\
\text { Iletkenliği }\end{array}$ & $\begin{array}{c}\text { İletkenlik azaldıkça, } \\
\text { çap artar. }\end{array}$ & $\begin{array}{l}\text { Zhang, C. ve } \\
\text { ark.[20] }\end{array}$ \\
\hline Nem & $\begin{array}{l}\text { Artan nem, çap1 } \\
\text { küçültür. }\end{array}$ & $\begin{array}{l}\text { Tripatanasuwan } \\
\text { ve ark.[21] }\end{array}$ \\
\hline
\end{tabular}

\subsection{Kimyasal Özellikler}

PLA ve PCL polimerlerinin kimyasal yapısını görebilmek için FTIR analizi yapılmış ve sonuçlar Şekil 3.1. ile Şekil 3.2.'de hazırlanmış solüsyonların FTIR sonuçları gösterilmiştir.

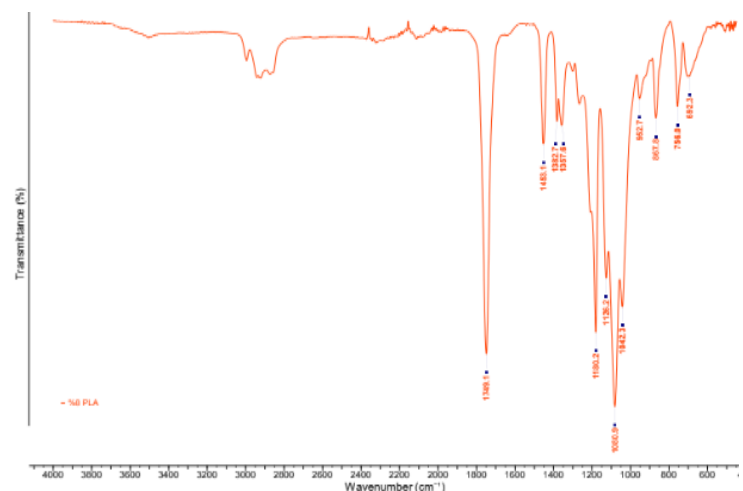

Şekil 3.1. PLA'nın FTIR analiz grafiği

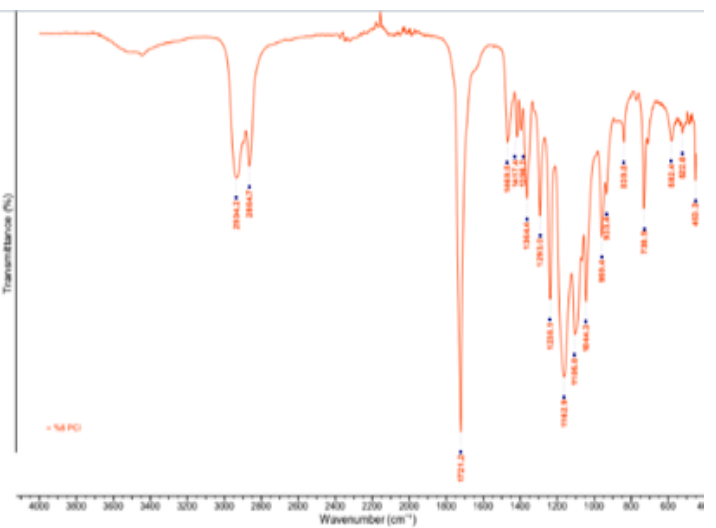

Şekil 3.2. PCL'in FTIR analiz grafiğgi 
FTIR spektrumlarına bakıldığında PLA doku iskelesinde tipik PLA $(1749,1453,1382,1357,1180$, 1126, 1080, 1042, 952, 862, 756, $692 \mathrm{~cm}^{-1}$ ) emme bantları gözlenmiştir. PLA'nın karakteristik özelliği olan omurga ester grubu $1749 \mathrm{~cm}^{-1}$ de göze çarpmaktadır. Ester gruplarının sebep olduğu -C-Otitreşim germe noktaları ise $1080-1180 \mathrm{~cm}^{-1}$ arası bölgede ortaya çıkmışlardır [22]. Son olarak da diğer karakteristik pik olan ve laktik asitlerin $\mathrm{OH}$ grupları olarak tanımlanan nokta $3640 \mathrm{~cm}^{-1}$ 'de gözlemlenmiştir [23].

PCL doku iskelesinin FTIR spektrumlarına bakıldığında ise PCL $(2934,2864,1721,1469,1417$, 1396, 1364, 1293, 1238, 1162 1105, 1044, 959, 933, $839,730,582,522,453 \mathrm{~cm}^{-1}$ ) absorpsiyon (emme) bantları gözlenmiştir. $\mathrm{PCL}$ 'in ester grubu $\mathrm{C}=\mathrm{O}, 1721$ $\mathrm{cm}^{-1}$ ve $\mathrm{C}-\mathrm{O}, 1162 \mathrm{~cm}^{-1}$ pik noktalarında azalan yoğunluk gözlenirken, sonradan artış göstermiştir [24]. $\mathrm{Bu}$ şekilde doku iskeleleri içinde yer alan materyallerin karakteristik özellikleri ortaya çıkarılmıştır.

\subsection{Morfolojik Özellikler}

Morfolojik yapı, yalnızca mekanik özelliklerin güçlendirilmesi konusunda yardımcı olmakla kalmayıp aynı zamanda hücrelerin hayatta kalmasını sağlayacak olan besin maddelerinin difüzyonunun kolaylaşmasına da sebep olmaktadır [25]. Damar iskelesi oluştururken kullanılan spinning (eğirme) parametreleri ve solüsyonun konsantrasyonu gibi etmenlerden etkilenirler. Sahip oldukları gözenek boyutları ve tiplerinden yola çıkarak uygun değer morfoloji yapısı seçilebilmektedir. Doku iskelesindeki gözenek büyüklüğünün arttırılması ve bu gözenek büyüklüklerinin mümkün olduğunca eş yapıll, birbirine benzeyen ve birbirine yakın olacak şekilde bir dağılım göstermesini biyouyumluluğu yükseltmektedir. $\mathrm{Bu}$ bilgiler dikkate alınarak, PLA'nı farklı konsantrasyonları için SEM görüntülerine ayrı ayrı bakılmıştır. Görüntülenen SEM sonuçları Şekil 3.3.(A,B,C) ve Şekil 3.4.(A,B,C)'de gösterilmiştir. PLA'nın \%8'lik (Şekil 3.3.A), PCL' in \%10'luk (Şekil 3.4.B) konsantrasyonları en iyi fiber yapıyı vermiş ve fiberler arası boşluk tespit edilmiştir. Devamında ise fiber yönelimi ve malzeme üretilebilirliği için en iyi örnek bulunmuştur.

\subsection{Mekaniksel Özellikler}

Çekme testinden geçirildikten sonra oluşan gerilmegerinim grafikleri PLA için Şekil $3.5^{\prime}$ te ve PCL için ise Şekil 3.6'da gösterilmiştir. Mekanik testlerden önce numuneler, $24^{\circ} \mathrm{C}$ 'de 48 saat bekletilmiştir. Her numuneden ise $4 \mathrm{~cm}$ uzunluğunda kesit alınmıştır.
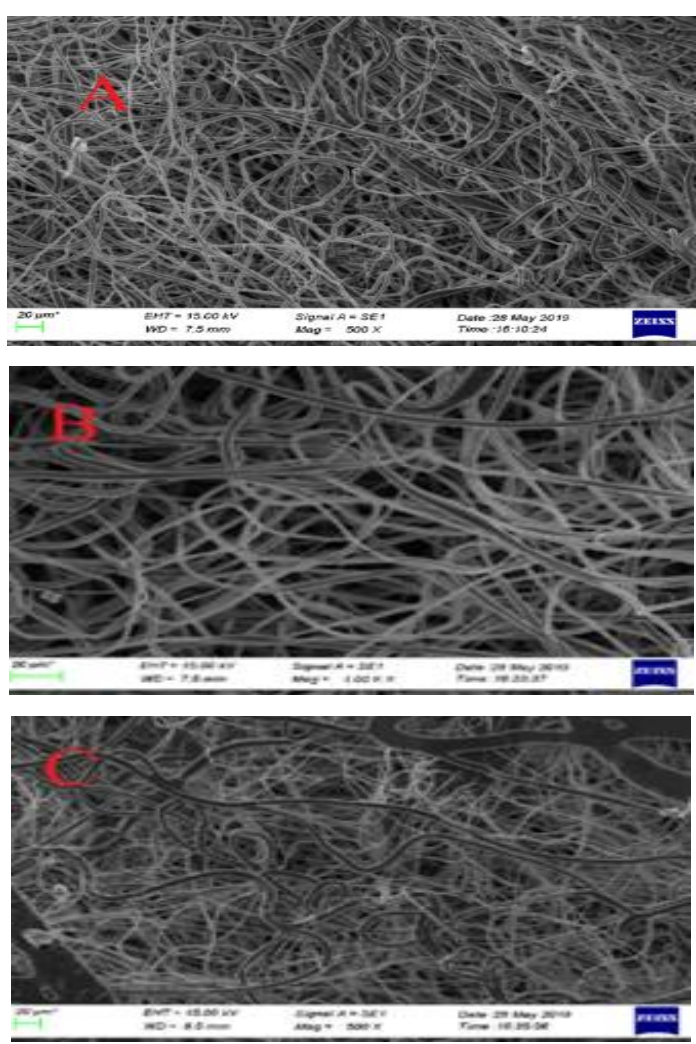
A) $\% 8$
B) $\% 10$
C) $\% 12$

Şekil 3.3. Farklı ağırlık oranlarında PLA'nın SEM görüntüleri
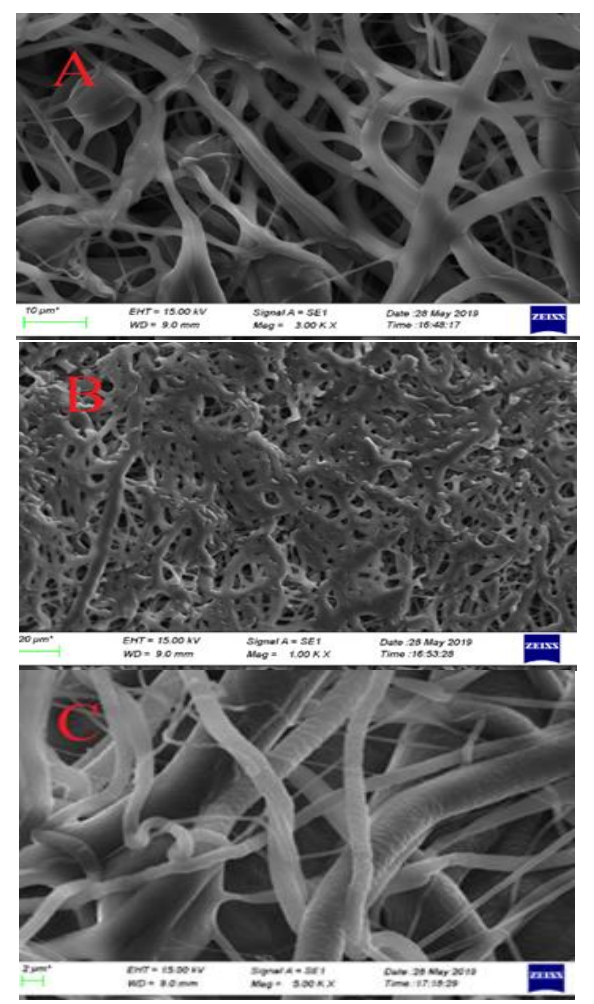

$\begin{array}{lll}\text { A) } \% 8 & \text { B) } \% 10 & \text { C) } \% 12\end{array}$

Şekil 3.3. Farklı ağırlık oranlarında PCL'nin SEM görüntüleri 


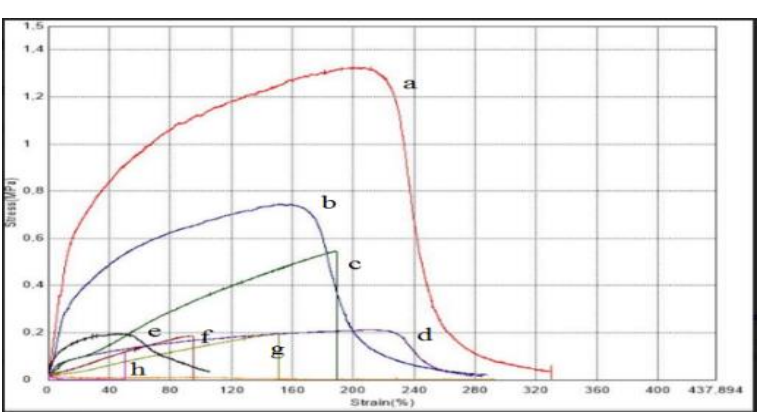

Şekil 3.5. PLA'nın farklı konsantrasyonlarının kalınlıklarda gerilme-gerinim grafiği

Şekil 3.5'de gerilme-gerinim grafiğinde farklı kalınlık ve farklı konsantrasyonlardaki dayanım oranları,

a) \%8'lik PLA için $2 \mathrm{~mm}$ kalınlığındaki kolektörde, Max gerilme 1,32 MPa iken gerinim \%211

b) \%8'lik PLA için $3 \mathrm{~mm}$ kalınlığındaki kolektörde, Max gerilme 0,75 MPa iken gerinim \%153

c) \%12'lik PLA için $3 \mathrm{~mm}$ kalınlığındaki kolektörde Max gerilme 0,54 MPa iken gerinim \%188

d) \%8'lik PLA için $5 \mathrm{~mm}$ kalınlığındaki kolektörde Max gerilme 0,21 MPa iken gerinim \%210

e) \%12'lik PLA'nın 2 mm kalınlığındaki kolektörde Max gerilme 0,19 MPa iken gerinim \%53

f) \%10'luk PLA'nın 4 mm kalınlığındaki kolektörde Max gerilme 0,18 MPa iken gerinim \%94

g) \%10'luk PLA'nın 5 mm kalınlığındaki kolektörde Max gerilme 0,19 MPa iken gerinim \%150

h) \%12'lik PLA'nın 5 mm kalınlığındaki kolektörde Max gerilme 0,11 MPa iken gerinim \%50

olarak bulunmuştur.

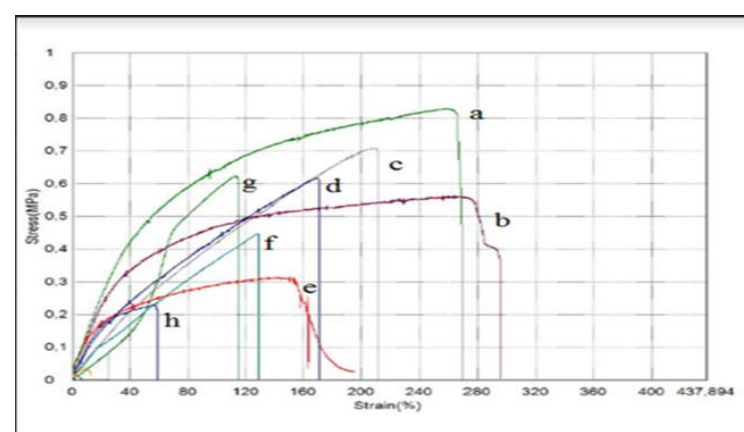

Şekil 3.6. PCL'in farklı konsantrasyonlarının kalınlıklarda gerilme-gerinim grafiği

Şekil 3.6'da gerilme gerinim grafığinde farklı kalınlık ve farklı konsantrasyonlardaki dayanım oranları ise,

a) \%10'luk PCL'in $2 \mathrm{~mm}$ kalınlığındaki kolektörde Max gerilme 0,82 MPa iken gerinim \%257

b) \%12'lik PCL'in $2 \mathrm{~mm}$ kalınlığında ki kolektörde Max gerilme 0,56 MPa iken gerinim \%264 c) \%10'luk PCL'in $5 \mathrm{~mm}$ kalınlığındaki kolektörde Max gerilme 0,70 MPa iken gerinim \%209

d) \%12'lik PCL'in $4 \mathrm{~mm}$ kalınlığındaki kolektörde Max gerilme 0,61 MPa iken gerinim \%169

e) \%12'lik PCL'in $3 \mathrm{~mm}$ kalınlığındaki kolektörde Max gerilme 0,31 MPa iken gerinim \%152

f) \%8'lik PCL'in $4 \mathrm{~mm}$ kalınlığındaki kolektörde Max gerilme 0,44 MPa iken gerinim \%128

g) \%10'luk PCL'in 4 mm kalınlığındaki kolektörde Max gerilme 0,62 MPa iken gerinim \%112

h) \%8'lik PCL'in 5 mm kalınlığındaki kolektörde Max gerilme 0,22 $\mathrm{MPa}$ iken gerinim $\% 55$

olarak bulunmuştur.

Çekme testi ile optimum konsantrasyon yüzdelerinin en iyi mekaniksel dayanım oranlarını sağladığı ve kollektör çapı arttırıldıkça bu mekanik özelliklerin düştüğü tespit edilmiştir.

\section{SONUÇ ve ÖNERI}

Elektrospinning yöntemi kullanarak farklı konsantrasyonlardaki PLA ve PCL polimerlerinden farklı kalınlıklarda yapay damar iskeleleri üretimi başarılı bir şekilde gerçekleştirilmiştir. \%8, \%10 ve $\% 12$ oranlarında hazırlanan solüsyonların fiziksel özellikleri tespit edilmiş ve bu fiziksel özellikler ile değiştirilen elektrospinning (elektroeğirme) parametrelerinin fiber yüzeyi ve çapına dolayısıyla da mekanik performansına olan etkileri incelenmiştir. İncelenen sonuçlar Tablo 3.1., Tablo 3.2. ve Tablo 3.3. de gösterilmiştir.

Elektrospinning (elektroeğirme) işlemiyle optimum fiber yapısını yakalamak ve pürüzsüz yüzey oluşturabilmek için parametreler değiştirilerek yapılan deneyler sonucunda, uygulanan voltajın $20.0 \mathrm{kV}$ ve akımın $1.5 \mathrm{ml} / \mathrm{h}$ dolaylarında kalmasının daha az baloncuklu yüzey oluşturduğu gözlemlenmiştir. Uç ile kollektör arasındaki mesafe arasında yapılan değişikliklerde $20 \mathrm{~cm}$ mesafenin uygun değer görülmüştür. Kolektörün dönüş hızı, yine kolektörün kendi kalınlığına bağlı olarak farklı seviyelerde incelenmiştir. Daha ince kolektörlerin daha hızlı döndürülmesiyle pürüzsüz yüzeyler ortaya çıkarılabilmiştir. Kalınlığ 2 mm olan kolektörlerde 70 rpm civarı optimum bulunmuşken, 3 mm'lik kolektörlerde $60 \mathrm{rpm}, 4$ ve $5 \mathrm{~mm}$ 'lik kolektörlerse ise $50 \mathrm{rpm}$ ve civarının daha iyi sonuçlar ortaya çıkardığı incelenmiş ve sonuçlar Tablo 2.2.1 ve Tablo 2.2.2'de gösterilmiştir.

Kimyasal, morfolojik ve mekaniksel olarak incelenen PLA solüsyonlarının SEM görüntülerine bakıldığında, gözenek büyüklüklerinin mümkün olduğunca eş yapılı ve birbirine yakın olacak şekilde uygun değer dağılımı yakaladığı konsantrasyonlar \%8 olarak bulunmuştur. PCL için ise bu konsantrasyon oranı \%10 olarak 
ölçülmüştür. Çekme testi sonuçlarından ise uygun değer konsantrasyon yüzdelerinin en iyi mekaniksel dayanım oranlarını sağladığı ve kolektör çapı arttırıldıkça bu mekanik özelliklerin düştüğü tespit edilmiştir.

$\mathrm{Bu}$ çalışmanın bir sonraki aşamasında imalatı gerçekleştirilen damar iskelelerinin hücre testi yapılarak canlı vücuduna adaptasyonu ve biyouyumluluğu test edilebilir.

\section{KAYNAKLAR}

[1] Chlupac J, Filova E, Bacakova L. Blood Vessel Replacement: 50 years of Development and Tissue Engineering Paradigms in Vascular Surgery, Physiol Res 2009;58:119-139.

[2] Shinoka, T., Imai, Y., Ikada, Y. Transplantation of a tissue-engineered pulmonary artery. N Engl J Med 344: 532-533, 2001.

[3] Bowlin Gary \& Sell Scott Creating small diameter bioresorbable vascular grafts through electrospinning, Journal of Materials Chemistry, 2008, 10.1039/b711848a.

[4] Ong, C. S., Fukunishi, T., Liu, R. H., Nelson, K., Zhang, H., Wieczorek, E., et al. (2017). Bilateral arteriovenous shunts as a method for evaluating tissue engineered vascular grafts in large animal models. Tissue Eng. Part C Methods 23, 728-735.

[5] Voorhees, A. B., Jr., Jaretzki, A., 3rd, Blakemore, A. H. The.

[6] Weinberg, C. B., Bell, E. A blood vessel model constructed from collagen and cultured vascular cells. Science 231: 397-400, 1986.

[7] Shinoka, T., Shum-Tim, D., Ma, P. X., et al. Creation of viable pulmonary artery autografts through tissue engineering. J Thorac Cardiovasc Surg 115: 536545; discussion 545-536, 1998.

[8] L'Heureux, N., Paquet, S., Labbe, R., et al. A completely biological tissue-engineered human blood vessel. FASEB J 12: 47-56, 1998.

[9] Niklason, L. E., Gao, J., Abbott, W. M., et al. Functional arteries grown in vitro. Science 284: 489493, 1999.

[10] Shum-Tim, D., Stock, U., Hrkach, J., et al. Tissue engineering of autologous aorta using a new biodegradable polymer. Ann Thorac Surg 68: 22982304; discussion 2305,1999.

[11] L'Heureux, N., McAllister, T. N., de la Fuente, L. M. Tissue-engineered blood vessel for adult arterial revascularization. N Engl J Med 357: 1451-1453, 2007. [12] Wise, S. G., Byrom, M. J., Waterhouse, A., Bannon, P. G., Ng, M. K., and Weiss, A. S. (2011). A multilayered synthetic human elastin/polycaprolactone hybrid vascular graft with tailored mechanical properties. Acta Biomater. 7, 295-303. 10.1016/j.actbio.2010.07.022
[13] G, N., Tan, A., Gundogan, B., Farhatnia, Y., Nayyer, L., Mahdibeiraghdar, S., et al. (2015). Tissue engineering vascular grafts a fortiori: looking back and going forward. Expert Opin. Biol. Ther. 15, 231-244. 10.1517/14712598.2015.980234.

[14] Horáková Jana, Design of Polycaprolactone Vascular Grafts, 2014, 10.1177/1528083714540701.

[15] Meechaisue, C., Dubin, R., Supaphol, P., Hoven, V. P., Kohn, J. (2006) Electrospunmat of tyrosinederived polycarbonate fibers for potential use astissue scaffolding material. 54 Journal of Biomaterial Science, PolymerEdition, 17, 1039-1056.

[16] Zuo, W., Zhu, M., Yang, W., Yu, H., Chen, Y., Zhang Y. (2005) Experimental study on relationship between jet instability and formation ofbeaded fibers during electrospinning. Polymer Engineering \& Science, 45, 704-709.

[17] Chase, G. G., Reneker, D. H. (2004) Nanofibers in filter media. Fluid/ParticleSeparation Journal, 16, 105117.

[18] Zheng, J., Long, Y. Z., Sun, B., Zhang, Z. H., Shao, F., Zhang, H. D., Zhang, Z. M., Huang J. Y. (2012) Polymer nanofibers prepared by low-voltage near-fieldelectrospinning. Chinese Physics B, 21, 048102, 1-6.

[19] Thompson, C. J., Chase, G. G., Yarin, A. L., Reneker, D. H. (2007) Effects of parameters on nanofiber diameter determined from electrospinning model. Polymer, 48, 6913-6922.

[20] Zhang, C. X., Yuan, X. Y., Wu, L. L., Han, Y., Sheng, J. (2005) Study on morphology of electrospun poly(vinyl alcohol) mats. European Polymer Journal, 41, 423-432.

[21] Tripatanasuwan, S., Zhong, Z. X., Reneker, D. H. (2007) Effect of evaporation andsolidification of the charged jet in electrospinning of poly(ethyleneoxide) aqueous solution. Polymer, 48, 5742-5746.

[22] Chen, C. C., Chueh, J. Y., Tseng, H., Huang, H. M., Lee, S. Y. (2003) Preparation and characterization of biodegradable PLA polymeric blends. Biomaterials, 24,1167-1173.

[23] Wei, X. P., Luo, Y. L., Xu, F., Chen, Y. S. (2016) Sensitive conductive polymer composites based on polylactic acid filled with multiwalled carbon nanotubes for chemical vapour sensing. Synthetic. Met, 215, 216-222.

[24] Elzein, T., Nasser-Eddine, M., Delaite, C., Bistac, S., Dumas, P. (2004) FTIR study of polycaprolactone chain organization at interfaces. Journal of Colloid and Interface Science, 73(2), 381-387.

[25] Charles-Harris, M., Koch, M. A., Navarro, M., Lacroix, D., Engel, E., Planell, J. A. A. (2008) A PLA/calcium phosphate degradable composite material for bone tissue engineering: an in vitro study. Journal of Materials Science: Materials in Medicine, 19(4), 1503-1513. 